\title{
The antimicrobial activity of silver acetate against Acinetobacter baumannii in a Galleria mellonella infection model
}

\author{
Eden Mannix-Fisher ${ }^{1}$, Samantha McLean ${ }^{\text {Corresp. } 1}$ \\ ${ }^{1}$ School of Science and Technology, Nottingham Trent University, Nottingham, United Kingdom \\ Corresponding Author: Samantha McLean \\ Email address: samantha.mclean@ntu.ac.uk
}

Background. The increasing prevalence of bacterial infections that are resistant to antibiotic treatment has caused the scientific and medical communities to look for alternate remedies aimed at prevention and treatment. In addition to researching novel antimicrobials, there has also been much interest in revisiting some of the earliest therapies used by man. One such antimicrobial is silver; its use stretches back to the ancient Greeks but interest in its medicinal properties has increased in recent years due to the rise in antibiotic resistance. Currently antimicrobial silver is found in everything from lunch boxes to medical device implants. Though much is claimed about the antimicrobial efficacy of silver salts the research in this area is mixed. Methods. Herein we investigated the efficacy of silver acetate against a carbapenem resistant strain of Acinetobacter baumannii to determine the in vitro activity of this silver salt against a World Health Organisation designated category I critical pathogen. Furthermore, we use the Galleria mellonella larvae model to assess toxicity of the compound and its efficacy in treating infections in a live host. Results. We found that silver acetate can be delivered safely to Galleria at medically relevant and antimicrobial levels without detriment to the larvae and that administration of silver acetate to an infection model significantly improved survival. This demonstrates the selective toxicity of silver acetate for bacterial pathogens but also highlights the need for administration of well-defined doses of the antimicrobial to provide an efficacious treatment. 


\section{The antimicrobial activity of silver acetate against}

2 Acinetobacter baumannii in a Galleria mellonella

3 infection model

4

5

6

7

8 9

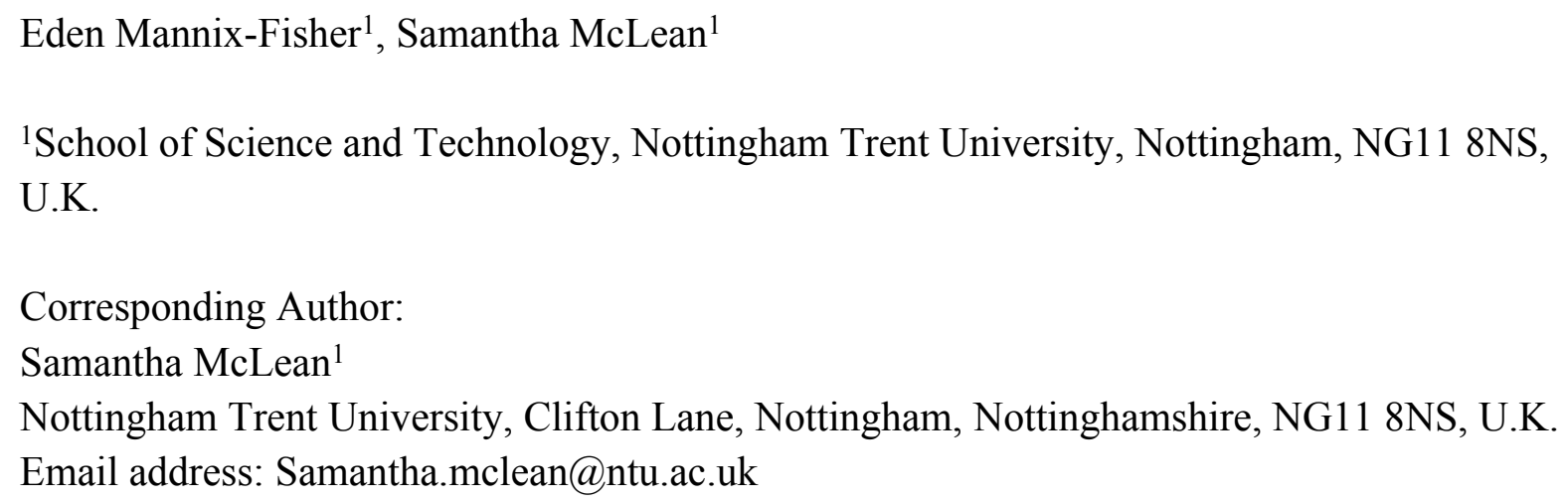

\section{Abstract}

Background. The increasing prevalence of bacterial infections that are resistant to antibiotic treatment has caused the scientific and medical communities to look for alternate remedies aimed at prevention and treatment. In addition to researching novel antimicrobials, there has also been much interest in revisiting some of the earliest therapies used by man. One such antimicrobial is silver; its use stretches back to the ancient Greeks but interest in its medicinal properties has increased in recent years due to the rise in antibiotic resistance. Currently antimicrobial silver is found in everything from lunch boxes to medical device implants. Though much is claimed about the antimicrobial efficacy of silver salts the research in this area is mixed.

Methods. Herein we investigated the efficacy of silver acetate against a carbapenem resistant strain of Acinetobacter baumannii to determine the in vitro activity of this silver salt against a World Health Organisation designated category I critical pathogen. Furthermore, we use the Galleria mellonella larvae model to assess toxicity of the compound and its efficacy in treating infections in a live host.

Results. We found that silver acetate can be delivered safely to Galleria at medically relevant and antimicrobial levels without detriment to the larvae and that administration of silver acetate to an infection model significantly improved survival. This demonstrates the selective toxicity of silver acetate for bacterial pathogens but also highlights the need for administration of welldefined doses of the antimicrobial to provide an efficacious treatment.

\section{Introduction}

The use of silver as an antimicrobial has been described throughout recorded history (Alexander, 2009) and though its popularity waned with the development and widespread use of antibiotics from the 1940's, the increasing global prevalence of antibiotic resistance amongst bacterial pathogens has reignited interest in this ancient remedy. Currently silver in different forms, is used to reduce the incidence and severity of infection in wound treatment via the application of 
40 topical suspensions and dressings (Atiyeh et al., 2007; Politano et al., 2013) as well as being 41 incorporated into indwelling medical devices such as vascular access grafts from companies 42 including B. Braun Medical Ltd. (B. Braun Melsungen AG) and Getinge AB. (Getinge AB).

43 Despite its apparent popularity as an antimicrobial the efficacy of silver treatments has met with 44 mixed results in the research community (Chopra, 2007; Politano et al., 2013) and manufacturer 45 efficacy claims are often difficult to verify due to a lack of access to raw data. Given these 46 limitations on determination of antimicrobial activity there is clear evidence that more

47 independent data is needed to better understand the antibacterial activity of silver compounds currently in use for treatment of infection. Herein we investigated the efficacy of a commercially used silver salt, silver acetate, against a WHO priority 1: critical pathogen; carbapenem-resistant Acinetobacter baumannii. Acinetobacter baumannii is a Gram-negative nosocomial pathogen. Its success as a nosocomial pathogen can be attributed to multiple factors including; the bacterium's ability to adhere to and thrive on abiotic and biotic surfaces, its capacity to form biofilms and its multi-drug resistance arising from a variety of mechanisms (McQueary \& Actis, 2011; Longo, Vuotto \& Donelli, 2014). Patients in intensive care units are most vulnerable to A. baumannii infection with manifestations varying due to point of entry including urinary tract infections, bacteraemia, secondary meningitis, wound infections and most commonly, ventilator associated pneumonia (Coenye et al., 2008; McQueary \& Actis, 2011). Many of these infections, such as those on catheters (Thallinger et al., 2014) and endotracheal tubing (Raad et al., 2011), are caused by the formation of biofilms increasing the difficulty for clinicians to clear the pathogen.

A. baumannii, an ESKAPE pathogen (Enterococcus faecium, Staphylococcus aureus, Klebsiella pneumoniae, Acinetobacter baumannii, Pseudomonas aeruginosa and Enterobacter species), is capable of multiple antibiotic resistances with many nosocomial strains isolated being multi-drug resistant and several strains identified as being pan-drug resistant (Kim et al., 2014). This led to the World Health Organisation assigning the carbapenem resistant strains of this species to the list of bacteria that pose the greatest threat to human health, specifically these strains are designated as Category I: critical, with the World Health Organisation encouraging prioritisation of research towards finding new means to combat infections caused by these strains (Tacconelli \& Magrini, 2017). Despite the obvious threat posed to human health by this pathogen, $A$. baumannii is the least studied of the ESKAPE pathogens and little research has been undertaken to understand the efficacy of silver salts such as silver acetate against this organism. $A$. baumannii strains have numerous mechanisms of antibiotic resistance including intrinsic resistance, enzymes that alter the antibiotic thereby reducing or eliminating activity, efflux pumps, modification of drug targets and permeability defects (Lin \& Lan, 2014).

Due to the rapid emergence of multi-drug resistant and pan-drug resistant strains of $A$. baumannii across the globe there is an increasing interest in development of antimicrobials including silver acetate as a potential means to combat these infections (World Health organisation, 2015). Silver has a long history of antimicrobial activity due to the ionisation of silver in water and bodily fluids to produce the silver ion, $\mathrm{Ag}^{+}$(Lansdown, 2006; Marx \& Barillo, 2014). Silver ions have a 
80 widespread effect on bacterial cells, firstly by interacting with residues on the cell membrane 81 including disulphides and phosphates to stimulate endocytosis of the ions. Once inside the cell, 82 the ionic silver interacts with cell membrane enzymes to cause denaturation of the cell envelope 83 and interacts with other vital enzymes that control respiration and replication (Marx \& Barillo, 84 2014). Importantly, due to the multiple targets of silver within a bacterial cell the emergence of 85 resistance is slow (Marx \& Barillo, 2014).

86 Also important in developing efficacious infection treatments is the selective toxicity of the 87 antimicrobial. Silver ions are thought to have low toxicity in the human body, often their accumulation after administration is transitory with minimal toxicity (Lansdown \& Williams, 2004; Lansdown, 2006) . Although silver ions have been found to accumulate in the organs and tissues of rats and humans at high doses (Drake \& Hazelwood, 2005; Loeschner et al., 2011) and permanent accumulation of silver can occur in the cornea and skin after prolonged exposure, this is not thought to be life threatening (Lansdown \& Williams, 2004; Lansdown, 2006) . The uptake of silver into the body during silver treatment has not been investigated in depth, however clinical studies have shown increased absorption through partial-thickness burns (Wang et al., 1985; Boosalis et al., 1987; Coombs et al., 1992).

One means of better understanding host toxicity without the need for human or animal trials that has gained popularity in recent years utilises Galleria mellonella larvae models. Galleria mellonella, commonly known as the greater wax moth, are insects within the order lepidoptera. Their larvae have a rudimentary immune system that can be said to mimic the mammalian immune system (Hernandez et al., 2019). By comparison to mammalian models, larvae are cheap to source in large numbers and do not require ethical approval. They are easy to manipulate experimentally, can survive in temperatures suitable for investigation of human pathogens ( 25 to $37^{\circ} \mathrm{C}$ ) and require no specialised equipment for maintenance. To ensure standardisation amongst assays larvae should be obtained from reputable suppliers (e.g. Bio Systems Technology $\operatorname{TruLarv}^{\mathrm{TM}}$ ) that guarantee the larvae are not treated with antibiotics and their growth conditions upon receipt have been standardised, so that larvae arrive in the same life stage with similar approximate dimensions. This makes the use of Galleria larvae in simple animal models of toxicity, infection and antimicrobial treatment highly favourable (Tsai, Loh \& Proft, 2016; Pereira et al., 2018; Hernandez et al., 2019) .

The aims of this study were to determine antimicrobial efficacy of silver acetate against $A$. baumannii in vitro, to identify the concentration of silver acetate that causes toxicity in the Galleria mellonella model and to determine whether this antimicrobial can rescue the larvae from lethal A. baumannii infection.

\section{Materials \& Methods}

\section{Strains and culture methods for Acinetobacter baumannii}

Strains were obtained from the American Type Culture Collection (ATCC), USA and the National Collection of Type Cultures (NCTC), UK. Strains were stored at $-80{ }^{\circ} \mathrm{C}$ as $20 \%$ glycerol stocks and were cultured on Mueller-Hinton agar and broth (Sigma Aldrich Ltd, UK) at $37^{\circ} \mathrm{C}$ unless otherwise stated. Strains in use are listed in Table 1. 
120

121

122

123

124

125

126

127

128

129

130

131

132

133

134

135

136

137

138

139

140

141

142

143

144

145

146

147

148

149

150

151

152

153

154

155

156

157

158

159

\section{Silver acetate}

Silver acetate was purchased from Sigma-Aldrich Ltd. Silver acetate stocks were prepared by dissolving in sterile distilled water and were stored protected from light at room temperature. Minimum inhibitory and bactericidal concentration assays

Overnight cultures of $A$. baumannii were diluted to $\mathrm{OD}_{600}=0.1$ in sterile phosphate buffered saline (PBS). Wells of 96-well plates were filled with $100 \mu 1$ Mueller-Hinton broth and silver acetate $\left(\left[1 \mathrm{mg} \mathrm{ml}^{-1}\right]\right.$ final $)$ or meropenem $\left(\left[0.01 \mathrm{mg} \mathrm{ml}^{-1}\right]\right.$ final) was added to wells in column one as appropriate. Two-fold serial dilutions were performed across the silver acetate plates while meropenem was diluted in $1 \mathrm{mg} \mathrm{ml}^{-1}$ increments. Subsequently $10 \mu 1$ diluted overnight culture was added to all test and positive control wells. Negative growth controls contained broth only. Plates were incubated statically at $37^{\circ} \mathrm{C}$ for $18 \mathrm{~h}$ in aerobic conditions. The minimum inhibitory concentration (MIC) was determined as the lowest concentration of compound where no visible growth was observed. Minimum bactericidal concentrations (MBCs) were determined by plating out $10 \mu \mathrm{l}$ spots of culture in triplicate onto Mueller-Hinton agar from every well where no growth was observed in the MIC assay. The MBC was determined as the lowest concentration of compound where growth could not be recovered.

\section{Growth in the presence of silver acetate}

Mueller-Hinton broth $(0.9 \mathrm{ml})$ was added to the wells of a 24-well plate, with a further addition of $0.1 \mathrm{ml}$ bacterial overnight culture diluted to $\mathrm{OD}_{600 \mathrm{~nm}}=0.5$. The plate was incubated at $37^{\circ} \mathrm{C}$ with orbital shaking $(4 \mathrm{~mm})$ in a Biotek ${ }^{\circledR}$ citation 3 imaging reader until absorbance of wells

reached an $\mathrm{OD}_{600 \mathrm{~nm}}$ of 0.3 . Silver acetate was added to wells at final concentrations of 15.6, 7.80, $3.91,1.95,0.98$ and $0 \mathrm{mg} \mathrm{L}^{-1}$. Growth was monitored every $20 \mathrm{~min}$ for $24 \mathrm{~h}$ and viability was measured every hour for the first eight hours.

\section{Biofilm assay}

Overnight cultures of $A$. baumannii were diluted to an $\mathrm{OD}_{600}=0.5$ in sterile PBS. Wells of 24well plates were filled with $1 \mathrm{ml}$ Mueller-Hinton broth and silver acetate was added to wells in column one to a final concentration of $7.8 \mathrm{mg} \mathrm{L}^{-1}$. Two-fold serial dilutions were performed across the plate. Subsequently $100 \mu 1$ diluted overnight culture was added to all test wells and positive control wells. Negative controls contained broth only. Plates were incubated statically at $37^{\circ} \mathrm{C}$ for 18 hours in aerobic conditions. Thereafter broth was aspirated, and biofilms were washed three times in $1 \mathrm{ml}$ sterile PBS. Wells were air dried and stained with $500 \mu 1$ of $0.1 \%$ (v/v) crystal violet for 1 hour. Stain was then removed, and wells were washed with PBS. Stain bound to the biofilm was solubilised with $200 \mu \mathrm{l}$ of ethanol. The $\mathrm{OD}_{540}$ of each well was measured using a BioTek ${ }^{\circledR}$ Cytation ${ }^{\mathrm{TM}} 3$ cell imaging multi-mode reader.

\section{Galleria mellonella}

Galleria mellonella larvae were purchased from TruLarv ${ }^{\mathrm{TM}}$, Biosystems Technology, Exeter, UK and were used immediately upon arrival. Larvae selected for use were healthy as demonstrated by a melanisation score of four and moving freely without stimulation. For all incubations $G$. melonella were placed in vented petri dishes on Whatman ${ }^{\mathrm{TM}}$ filter paper. For each experiment, groups of ten larvae were used per condition and all experiments were repeated a 
160 minimum of three times on different dates ensuring that each condition was tested with a

161

162

163

164

165

166

167

168

169

170

171

172

173

174

175

176

177

178

179

180

181

182

183

184

185

186

187

188

189

190

191

192

193

194

195

196

197

198

199

minimum of thirty larvae from different batches of Galleria.

\section{Inoculum testing}

Cultures of A. baumannii NCTC 13302 were incubated overnight, then washed in PBS to remove residual media and diluted to the appropriate concentration. Healthy larvae were infected with bacterial cultures, equating to $1.7 \times 10^{2}, 1.7 \times 10^{3}, 1.7 \times 10^{4}, 1.7 \times 10^{5}, 1.7 \times 10^{6}$, or $1.7 \times 10^{7}$ CFU per larvae in a final volume of $10 \mu \mathrm{l}$ by injection into the last left proleg. Control groups were injected with $10 \mu \mathrm{PBS}$ or were not injected. Larvae were incubated at $37^{\circ} \mathrm{C}$ for four days and were monitored for melanisation score and survival every $24 \mathrm{~h}$ post-injection.

\section{Toxicity assays}

Healthy larvae were injected in the last left proleg with $10 \mu \mathrm{l}$ water containing silver acetate at a final concentration of $1.25,2.5,5,10,20,40$ or $80 \mathrm{mg} \mathrm{kg}^{-1}$ animal weight. Control groups were injected with $10 \mu 1$ water or were not injected. Larvae were incubated for four days at $37^{\circ} \mathrm{C}$ with survival and melanisation scoring carried out every $24 \mathrm{~h}$ post-injection.

\section{Treatment assays}

Cultures of A. baumannii NCTC 13302 were incubated overnight, then washed in PBS and diluted to the appropriate concentration. Healthy larvae were injected with A. baumannii that equated to $1.7 \times 10^{5}$ or $1.7 \times 10^{6} \mathrm{CFU}$ per larvae in the last left proleg. Following a $30 \mathrm{~min}$ incubation at $37^{\circ} \mathrm{C}$, a second injection was administered containing 0,10 or $20 \mathrm{mg} \mathrm{kg}^{-1}$ animal weight of silver acetate into the last right proleg. Larvae were incubated for four days at $37{ }^{\circ} \mathrm{C}$ with survival and melanisation scoring carried out every $24 \mathrm{~h}$ post-injection.

\section{Statistical analyses}

Statistical analysis to determine the significance of difference in Galleria mellonella larval survival between different conditions used the Log rank (Mantel-cox) test. Analysis of biofilm formation and larval health scores used two-way ANOVA with Tukey's multiple comparison.

\section{Results}

\section{Silver acetate demonstrates antimicrobial activity against Acinetobacter baumannii}

To first demonstrate the antimicrobial activity of silver acetate five strains of $A$. baumannii were tested to determine the minimum inhibitory and bactericidal concentrations of this silver salt for each strain. The minimal inhibitory concentration (MIC) of silver acetate was found to be 4.56 $\mathrm{mg} \mathrm{L}^{-1}$ or lower for all strains tested, demonstrating the antibacterial activity of silver acetate against this species (Table 1).

To confirm whether the mechanism of antimicrobial activity of silver acetate was growth inhibition or killing in this species; minimum bactericidal concentration (MBC) assays were performed. In all strains the MBC did not significantly differ from the MIC for silver acetate suggesting a bactericidal mechanism of action (Table 1).

To evaluate the antimicrobial activity of silver acetate against $A$. baumannii to a greater extent the WHO priority 1: critical pathogen strain NCTC 13302 was chosen for further study.

\section{The permanence of silver acetate toxicity against exponentially growing Acinetobacter} baumannii is concentration dependent 
200 Frequently antibiotic intervention commences when the infection is established, and bacterial 201 load is high with the pathogen actively growing. Considering this we sought to determine how 202 exposure of exponentially growing bacteria to silver acetate at a range of concentrations 203 impacted growth and viability.

204 Exponentially growing cultures of $A$. baumannii NCTC 13302 were established before the 205 addition of varying concentrations of silver acetate that centered around the MIC for this strain. 206 When cultures were exposed to concentrations of silver acetate below the recorded MIC (3.91mg $207 \mathrm{~L}^{-1}$ ) no significant decrease in growth was observed compared to the control (Fig. 1A and 1B). 208 However, at concentrations above the MIC (7.8 and $\left.15.6 \mathrm{mg} \mathrm{L}^{-1}\right)$ loss of growth was rapid and 209 permanent (Fig. 1D and 1E) Interestingly, exponentially growing cultures exposed to the MIC of 210 silver acetate $\left(3.91 \mathrm{mg} \mathrm{L}^{-1}\right)$ showed a biphasic effect with inhibition of growth within the first ten 211 hours after exposure but growth recovery over the following 14 hours (Fig. 1C).

212 To understand whether the silver acetate mechanism of action was bactericidal as suggested by 213 the MIC and MBC assays (Table 1) viability assays were conducted on the cultures immediately 214 prior to and at regular intervals after addition of silver acetate. Viability did not appear to be 215 impacted when silver acetate was administered below the MIC but when administered at a 216 concentration of double the MIC or higher there was a significant decrease in viability from two 217 hours, with complete loss of viability at six hours (Fig. 2). When exposed to silver acetate at the 218 MIC, A. baumannii viability decreased 10-fold after two hours and 65-fold by eight hours, 219 however these were modest decreases in viability that were recovered by $24 \mathrm{~h}$ (Fig. 2) suggesting 220 that relatively few cells were killed in cultures exposed to this concentration of silver acetate and 221 highlighting the need for appropriate dosing when using silver salts as antimicrobial agents.

222 Biofilm formation in Acinetobacter baumannii is inhibited by silver acetate

223 Biofilm formation is a major cause of infection and mortality. A. baumannii is known to readily 224 form biofilms under numerous clinically relevant conditions, therefore we sought to determine 225 whether silver acetate was effective in reducing biofilm formation.

226 Cultures of $A$. baumannii were incubated statically in a 24 -well plate at $37^{\circ} \mathrm{C}$ for $18 \mathrm{~h}$ in 227 Mueller-Hinton broth containing concentrations of silver acetate ranging from 0 to $7.81 \mathrm{mg} \mathrm{L}^{-1}$. 228 After incubation the amount of biofilm formation and number of viable cells were determined 229 using crystal violet staining and viability assays respectively. At concentrations below the MIC, 230 there was no significant difference in the amount of biofilm formed compared to the negative 231 control. However, when bacteria were incubated with higher concentrations of silver acetate (3.9 $\left.232-7.8 \mathrm{mg} \mathrm{L}^{-}\right)$, there was a significant reduction in biofilm formation $(<0.0001$, Fig. $3 \mathrm{~A})$.

233 Enumeration of viable cells within the biofilms also showed no significant difference between 234 the viability of cells exposed to silver acetate concentrations below the MIC compared to the 235 negative control. At higher silver salt concentrations $(3.9-7.8 \mathrm{mg} \mathrm{L})$ survival was reduced 236 significantly $(\mathrm{P}<0.005$, Fig. 3B).

\section{Infection of Galleria mellonella with Acinetobacter baumannii causes a lethal infection}

238 Over the past decade Galleria mellonella larvae have become an established model for analysing 239 the virulence and pathogenesis of human bacterial pathogens and in the testing of novel 
240 antimicrobial compounds. Initial testing in this study sought to determine the virulence of $A$.

241 baumannii strain NCTC 13302 using a G. mellonella infection model. Here, the larvae were

242 divided into groups and injected in the last left proleg with $10 \mu \mathrm{l}$ of the appropriate number of

243 bacteria $\left(1.7 \times 10^{2}-1.7 \times 10^{7}\right.$ cells per larvae), PBS (vehicle control) or were not injected (no

244 injection control). The larvae we incubated at $37^{\circ} \mathrm{C}$ and monitored for changes in health every

$24524 \mathrm{~h}$ over the following four days. To ensure that batch variations did not bias the results, this

246 experiment was repeated three times with different batches of larvae purchased on different

247 dates. In total, 30 larvae per condition were tested.

248 Fig. 4A shows survival of the larvae over four days, with the lowest concentration of bacteria

249 injected causing no significant difference in larval death compared to the negative controls. The

250 highest concentration of bacteria killed all larvae within $24-48 \mathrm{~h}$ and intermediate

251 concentrations caused significantly different levels of killing over four days $(\mathrm{P}<0.0001)$. The

252 immune system of G. mellonella includes a cellular response called melanisation. This cellular

253 response is used to trap microbes, but also makes it possible to track the immune response and

254 health of the larvae via visible colour change (Wojda, 2017). Melanisation of the larvae was

255 monitored as an indicator of health and supported the survival data with decreased health

256 observed with increase bacterial load and significant variation in health across the higher

257 concentrations of bacteria in comparison to the no infection controls (Fig. 4).

258 A range of silver acetate concentrations commonly used in antibiotic therapy shows

259 minimal toxicity to Galleria mellonella

260 For an antimicrobial to be appropriate for therapy it should display two key features:

261

262 antimicrobial activity against the target pathogen(s) and minimal toxicity towards the host. We

\section{3 a variety of clinically relevant concentrations.}

264 Galleria were divided into groups and were injected with silver acetate in concentrations ranging 265 from $1.25-80 \mathrm{mg} \mathrm{kg}^{-1}$ of animal weight (approximately $0-24 \mu \mathrm{g}$ per larvae). Negative control groups included larvae that were injected with water or were not injected. The experiment was repeated in temporally spaced triplicate to account for batch to batch variations in the larvae and collectively 30 larvae were tested per condition.

269 The data demonstrated that only the $80 \mathrm{mg} \mathrm{kg}^{-1}$ dosage of silver acetate caused persistent larval

270 death of $\sim 10 \%$ (Fig. 5A), although no significant difference between the survival of larvae at the 271 different concentrations was observed $(\mathrm{P}=0.0524)$. The melanisation scores showed that only 272 larvae exposed to the highest concentration of silver acetate produced visible melanisation (Fig.

273 5B). A significant difference in melanisation developed between the $80 \mathrm{mg} \mathrm{kg}^{-1}$ injected larvae 274 and no silver acetate controls from $72 \mathrm{~h}$ onwards.

275 Treatment of Acinetobacter baumannii infection with silver acetate causes increased 276 survival

277 To address whether silver acetate is an effective antimicrobial against infection in a Galleria 278 mellonella infection model, larvae were injected with concentrations of bacteria that would cause 279 significant death within four days without intervention (Fig. 3, $1.7 \times 10^{5}$ and $1.7 \times 10^{6}$ cells per 
280 larvae). Thirty minutes post-infection the larvae were administered with either 10 or $20 \mathrm{mg} \mathrm{kg}^{-1}$ 281 silver acetate, both concentrations having demonstrated minimal toxicity towards Galleria (Fig. 282 5). As with previous experiments the Galleria were tested in groups of ten larvae. To ensure 283 statistical significance of the results and to account for batch to batch variations with the larvae 284 this experiment was repeated seven times with a total of 70 larvae tested per condition across all 285 repeats.

286 Larvae injected with the $\sim 10^{5}$ bacterial cells were better able to survive than larvae injected with 287 the $\sim 10^{6}$ bacterial cells in all conditions. Larvae treated with either concentration of silver acetate 288 showed significant increase in survival $(\mathrm{P}<0.05$, Fig. 6). Larvae infected with the lower 289 infectious dose of $A$. baumannii showed a $20 \%$ increase in survival after treatment with silver 290 acetate (Fig. 6A). For larvae receiving the higher infectious dose, $10 \mathrm{mg} \mathrm{kg}^{-1}$ silver acetate 291 treatment caused larval survival to increase by $31 \%$ and treatment with $20 \mathrm{mg} \mathrm{kg}^{-1}$ silver acetate 292 increased larval survival by $27 \%$ (Fig. 6B).

293 Correlating with the increased survival, improved larval health was also observed when silver 294 acetate treatment was administered (Fig. 6C and 6D). As with the infection studies (Fig. 4) the 295 melanisation score of larvae injected with both $\sim 10^{5}$ and $\sim 10^{6}$ bacterial cells showed a reduction 296 in health from $48 \mathrm{~h}$. However, after silver acetate treatment of Galleria infected with $\sim 10^{5}$ 297 bacterial cells, differences in melanisation between the treated and non-treated larvae became 298 significant after $72 \mathrm{~h}(\mathrm{P}<0.042)$. For Galleria infected with $\sim 10^{6}$ bacterial cells, significant 299 differences appeared between the non-treated larvae and the larvae treated with both 300 concentrations of silver acetate at $96 \mathrm{~h}(\mathrm{P}<0.009)$.

301

\section{Discussion}

303 Silver salts are incorporated into many commercially available, indwelling medical devices to 304 provide antimicrobial activity during implantation for protection against infection during the 305 time when the risk of infection is highest. Similarly, silver is also incorporated into wound 306 dressings to provide antimicrobial activity against infected wounds (Leaper et al., 2012; National 307 Institute for Helth and Care Excellence, 2020). The data presented herein sought to gain a better 308 understanding of the antimicrobial efficacy and host toxicity of silver acetate to provide further 309 insight into its potential value in infection control.

310 Silver acetate proved to be an effective antimicrobial in vitro for all A. baumannii strains tested 311 with minimal inhibitory and bactericidal concentrations in the range of many clinically relevant 312 antibiotics as assessed using standardised methods for determination of MIC and MBC values 313 (The European Committee on Antimicrobial Susceptibility Testing, 2019). This included strains 314 with limited antibiotic resistance and those with multiple resistances suggesting that existing 315 antibiotic resistance mechanisms do not cause increased resistance to silver. Additionally, these 316 values are broadly similar to reported MIC values for this species against silver nitrate $\left(2.5 \mathrm{mg} \mathrm{L}^{-}\right.$ 317 1', (Wan et al., 2016)) and silver ions (3.9 $\mathrm{mg} \mathrm{L}^{-1}$, (Vaidya et al., 2017)). This is expected due to 318 the antimicrobial mechanisms of silver acetate being caused by the silver ions in solution with 319 the salt itself being largely inert in terms of antimicrobial activity. Silver ions are able to bind to 
320

321

322

323

324

325

326

327

328

329

330

331

332

333

334

335

336

337

338

339

340

341

342

343

344

345

346

347

348

349

350

351

352

353

354

355

356

357

358

359

the bases of DNA and RNA (Arakawa, Neault \& Tajmir-Riahi, 2001), which is thought to be responsible for bacterial mutation and issues with replication, however this has yet to be proven in vivo. Silver ions cause numerous disruptions to proteins within the bacterial cell. Silver ions can bind to sulfhydryl groups on amino acids, disrupting protein function (Russell \& Hugo, 1994), they are thought to disrupt iron-sulfur clusters (Xu \& Imlay, 2012), thiol groups and sulfhydryl-liganded metals (Morones-Ramirez et al., 2013). There is also evidence of the role for silver in membrane disruption causing enhanced permeability (Morones-Ramirez et al., 2013; Vazquez-Muñoz et al., 2019). With this multitude of targets, it is perhaps unsurprising that antibiotic resistant strains are still susceptible to silver ions. Increased bactericidal activity has been reported via the production of silver nanoparticles. The size and shape of these silver nanoparticles play a key role in their bactericidal activity (Pal, Tak \& Song, 2007).

The issue of resistance to silver compounds developing due to widespread use has been a topic of much debate. Whilst some research has suggested that the resistance to silver is slow to emerge and mild due to the requirement of the bacterium to develop resistances that nullify several of the above mentioned mechanisms of action (Marx \& Barillo, 2014), others have described various mechanisms of silver resistance that is emerging across the globe. One such mechanism is the production of redox active metabolites, for example the production of pyocyanin by

Pseudomonas aeruginosa has been demonstrated to not only protect itself but also other species of bacteria in close proximity to the phenazine compound (Muller, 2018). This is a concern as $P$. aeruginosa is frequently isolated from polymicrobial infections. Another mechanism of silver resistance described in the literature is the increased expression or acquisition via horizontal gene transfer of the sil system (Hosny et al., 2019). This collection of genes primarily reduces intracellular accumulation of silver inside the cell by expressing periplasmic proteins that bind silver preventing further penetration into the cell and by expressing silver efflux pumps. This and the data provided herein highlights the importance of strict monitoring of silver use as an antimicrobial and administration of the appropriate dosages when used.

This study focused on the antimicrobial activity of silver acetate against the lesser studied ESKAPE pathogen; A. baumannii. The data herein demonstrates a similar trend in antimicrobial activity to this bacterial species as others have reported for more widely studied pathogens including Staphylococcus aureus with MIC's in the range of $0.08-32 \mathrm{mg} \mathrm{L}^{-1}$, Pseudomonas aeruginosa with MIC's of $0.04-8 \mathrm{mg} \mathrm{L}^{-1}$ and Escherichia coli with MIC's of $0.5-2.5 \mathrm{mg} \mathrm{L}^{-1}$ (Peetsch et al., 2013; Zhang et al., 2015; Oates et al., 2018; Shah et al., 2020).

As well as the concentration at which antimicrobials can inhibit growth or kill bacterial pathogens another important property is the speed with which they are able to exert these effects. Herein we have demonstrated that exponentially growing cultures suffered a four-log reduction in viability at silver acetate concentrations similar to the minimal bactericidal concentration within two hours exposure. Higher concentrations of the silver salt showed almost complete cell death by this time (Fig. 2) and six hours post-exposure concentrations $>7.8 \mathrm{mg} \mathrm{L}^{-1}$ caused a complete loss of viability. Other studies have also demonstrated both a time and concentration dependent killing of bacteria upon exposure to silver (Jaime-Acuña et al., 2016). Here, a silver- 
360 based nanocomposite was used to demonstrate the time and concentration dependent killing of

361

362

363

364

365

366

367

368

369

370

371

372

373

374

375

376

377

378

379

380

381

382

383

384

385

386

387

388

389

390

391

392

393

394

395

396

397

398

399

\section{Escherichia coli.}

Besides antimicrobial activity, a key factor in determination of whether silver acetate is suitable as an effective treatment for infection or prophylaxis is its toxicity to the host. Selective toxicity has been a cornerstone of antimicrobial therapy since Paul Ehrlich first proposed the concept by stating that the optimal agents would combine high parasitotropism with low organotropism (Witkop, 1999). Galleria mellonella is increasingly used as an ethically viable alternative to mammalian models for testing toxicity of compounds to the host (Dolan et al., 2016; Aneja et al., 2018; Cruz et al., 2018; Lazarini et al., 2018). One recent study compared the toxicity of exposure to eight different food preservatives in both Galleria mellonella and rat models, concluding that there was a strong correlation between the $\mathrm{LD}_{50}$ values of those preservatives in G. mellonella larvae and rats providing evidence of the suitability of this model for preliminary toxicity testing (Maguire, Duggan \& Kavanagh, 2016).

In our study toxicity testing in the G. mellonella model revealed that only the highest concentration of silver acetate tested ( $80 \mathrm{mg} \mathrm{kg}^{-1}$ animal weight) caused significant death of the larvae. Therapeutic ranges of antimicrobials can be as low as $5 \mathrm{mg} \mathrm{kg}^{-1}$ daily to up to $85 \mathrm{mg} \mathrm{kg}^{-1}$ for urinary tract infections caused by indwelling catheters (National Institute for Health and Care Excellence, 2018). The dose depends on the administration method and the severity of the infection; however, most doses administered are less than $20 \mathrm{mg} \mathrm{kg}^{-1}$. As $10-20 \mathrm{mg} \mathrm{kg}^{-1}$ silver acetate showed no detrimental effects on the larvae here, it can be concluded that these are safe therapeutic doses in this model. Additionally, these low doses were able to significantly improve survival of the larvae after infection with a carbapenem-resistant strain of $A$. baumannii

providing promising data for the clearance of drug-resistant bacterial pathogens.

The inoculum study revealed that $\sim 10^{6}$ bacterial cells per larvae was able to cause $80 \%$ larval death, which is an appropriate amount of mortality for subsequent treatment studies (Ignasiak \& Maxwell, 2017). For comparison, a 10-fold lower infectious dose was also tested. The survival of larvae injected with $\sim 10^{5}$ bacteria cells increased by $20 \%$ at both concentrations of silver acetate used to treat the infection, while for the 10-fold higher infectious dose, survival increased by $27 \%$ and $31 \%$ for treatment with 20 and $10 \mathrm{mg} \mathrm{kg}^{-1}$ doses respectively. Future research could utilise this statistically significant improvement in survival upon administration of silver acetate in combination with antibiotic treatment to look for increased antimicrobial activity. Previous studies have demonstrated the potential synergy of silver ions with established antibiotics of the $\beta$-lactam, quinolone and aminoglycoside groups (Morones-Ramirez et al., 2013). More recently, silver nanoparticles have demonstrated synergy and additive effects when used in conjunction with antibiotics including kanamycin and chloramphenicol respectively (Vazquez-Muñoz et al., 2019). Here, membrane disruption was identified as a mechanism of action that improved antibiotic activity by allowing improved access to intracellular targets for these antibiotics. Further study of the adjuvant effects of silver acetate against drug resistant bacterial pathogens when administered alongside antibiotics currently on the market could provide a new route to antimicrobial treatment of these pathogens.

Peer) reviewing PDF | (2020:11:55546:1:1:NEW 1 Mar 2021) 
400 In conclusion the data presented here demonstrates the efficacy of silver acetate as an

401 antimicrobial against carbapenem resistant Acinetobacter baumannnii. We demonstrate that this

402 silver salt is non-toxic to Galleria mellonella at concentrations able to cause significant

403 antimicrobial activity and further that the administration of silver acetate can improve survival of

404 infected larvae. Together this data suggests silver acetate is a suitable silver salt candidate for

405 antimicrobial therapy when administered at an appropriate concentration.

406 Conclusions

407 Herein we sought to determine the antimicrobial efficacy of silver acetate against a carbapenem

408 resistant strain of Acinetobacter baumannii both in vitro and in an in vivo Galleria mellonella

409 infection model. We found that silver acetate had bactericidal effects on the pathogen, was able

410 to reduce biofilm formation and was able to significantly improve the survival of Galleria

411 mellonella infected with otherwise lethal doses of $A$. baumannii. This data shows that silver

412 acetate may be used as an effective antimicrobial at concentrations that are not damaging to the

413 host and support the hypothesis that it can be used in efficacious antimicrobial therapy.

414

415

Acknowledgements

416

417

The authors would like to thank Hannah Southam for assistance in development of the Galleria mellonella models.

418

419

420

421

422

423

424

425

426

427

428

429

430

431

432

433

434

435

436

437

438

439

440

441

442

\section{References}

Alexander JW. 2009. History of the medical use of silver. Surgical Infections 10:289-292. DOI: 10.1089/sur.2008.9941.

Aneja B, Azam M, Alam S, Perwez A, Maguire R, Yadava U, Kavanagh K, Daniliuc CG, Rizvi MMA, Haq QMR, Abid M. 2018. Natural Product-Based 1,2,3-Triazole/Sulfonate Analogues as Potential Chemotherapeutic Agents for Bacterial Infections. ACS Omega 3:6912-6930. DOI: 10.1021/acsomega.8b00582.

Arakawa H, Neault JF, Tajmir-Riahi HA. 2001. Silver(I) Complexes with DNA and RNA Studied by Fourier Transform Infrared Spectroscopy and Capillary Electrophoresis. Biophysical Journal 81:1580-1587.

Atiyeh BS, Costagliola M, Hayek SN, Dibo SA. 2007. Effect of silver on burn wound infection control and healing: Review of the literature. Burns 33:139-148. DOI: 10.1016/j.burns.2006.06.010.

B. Braun Melsungen AG.No Title. Available at https://www.bbraun.com/en/products/b/silvergraft.html (accessed April 15, 2020).

Boosalis MG, McCall JT, Ahrenholz DH, Solem LD, McClain CJ. 1987. Serum and urinary silver levels in thermal injury patients. Surgery 101:40-43.

Chopra I. 2007. The increasing use of silver-based products as antimicrobial agents: A useful development or a cause for concern? Journal of Antimicrobial Chemotherapy 59:587-590. DOI: $10.1093 / \mathrm{jac} / \mathrm{dkm} 006$.

Coenye T, De Prijck K, De Wever B, Nelis HJ. 2008. Use of the modified Robbins device to study the in vitro biofilm removal efficacy of NitrAdine ${ }^{\mathrm{TM}}$, a novel disinfecting formula for the maintenance of oral medical devices. Journal of Applied Microbiology 105:733-740. DOI: 10.1111/j.1365-2672.2008.03784.x. 
443 Coombs CJ, Wan AT, Masterton JP, Conyers RAJ, Pedersen J, Chia YT. 1992. Do burn patients

444 have a silver lining? Burns 18:179-184. DOI: https://doi.org/10.1016/0305-4179(92)90067$445 \quad 5$.

446 Cruz LIB, Lopes LFF, Ribeiro F de C, de Sá NP, Lino CI, Tharmalingam N, de Oliveira RB, 447

448

449

450

451

452

453

454

455

456

457

458

459

460

461

462

463

464

465

466

467

468

469

470

471

472

473

474

475

476

477

478

479

480

481

482

483

484

485

486

487

488 Rosa CA, Mylonakis E, Fuchs BB, Johann S. 2018. Anti-Candida albicans activity of thiazolylhydrazone derivatives in invertebrate and murine models. Journal of Fungi 4:1-14. DOI: $10.3390 /$ jof4040134.

Dolan N, Gavin DP, Eshwika A, Kavanagh K, McGinley J, Stephens JC. 2016. Synthesis, antibacterial and anti-MRSA activity, in vivo toxicity and a structure-activity relationship study of a quinoline thiourea. Bioorganic and Medicinal Chemistry Letters 26:630-635. DOI: $10.1016 / \mathrm{j} . \mathrm{bmcl} .2015 .11 .058$.

Drake PL, Hazelwood KJ. 2005. Exposure-related health effects of silver and silver compounds: A review. Annals of Occupational Hygiene 49:575-585. DOI: 10.1093/annhyg/mei019.

Getinge AB.No Title. Available at https://www.getinge.com/int/product-catalog/intergard-silver/ (accessed April 15, 2020).

Hernandez RJ, Hesse E, Dowling AJ, Coyle NM, Feil EJ, Gaze WH, Vos M. 2019. Using the wax moth larva Galleria mellonella infection model to detect emerging bacterial pathogens. PeerJ 2019:1-13. DOI: 10.7717/peerj.6150.

Hosny AEDMS, Rasmy SA, Aboul-Magd DS, Kashef MT, El-Bazza ZE. 2019. The increasing threat of silver-resistance in clinical isolates from wounds and burns. Infection and Drug Resistance 12:1985-2001. DOI: 10.2147/IDR.S209881.

Ignasiak K, Maxwell A. 2017. Galleria mellonella (greater wax moth) larvae as a model for antibiotic susceptibility testing and acute toxicity trials. BMC Research Notes 10:1-8. DOI: 10.1186/s13104-017-2757-8.

Jaime-Acuña OE, Meza-Villezcas A, Vasquez-Peña M, Raymond-Herrera O, VillavicencioGarcía H, Petranovskii V, Vazquez-Duhalt R, Huerta-Saquero A. 2016. Synthesis and complete antimicrobial characterization of CEOBACTER, an Ag-Based nanocomposite. PLoS ONE 11:1-18. DOI: 10.1371/journal.pone.0166205.

Kim UJ, Kim HK, An JH, Cho SK, Park K-H, Jang H-C. 2014. Update on the Epidemiology, Treatment, and Outcomes of Carbapenem-resistant Acinetobacter infections. Chonnam Medical Journal 50:37. DOI: 10.4068/cmj.2014.50.2.37.

Lansdown ABG. 2006. Silver in health care: Antimicrobial effects and safety in use. Current Problems in Dermatology 33:17-34. DOI: 10.1159/000093928.

Lansdown ABG, Williams A. 2004. How safe is silver in wound care? Journal of wound care 13:131-136. DOI: 10.12968/jowc.2004.13.4.26596.

Lazarini JG, Sardi J de CO, Franchin M, Nani BD, Freires IA, Infante J, Paschoal JAR, de Alencar SM, Rosalen PL. 2018. Bioprospection of Eugenia brasiliensis, a Brazilian native fruit, as a source of anti-inflammatory and antibiofilm compounds. Biomedicine and Pharmacotherapy 102:132-139. DOI: 10.1016/j.biopha.2018.03.034.

Leaper D, Ayello EA, Carville K, Fletcher J, Keast DH. 2012. Appropriate Use of Silver. Wounds International:2-24.

Lin M-F, Lan C-Y. 2014. Antimicrobial resistance in Acinetobacter baumannii: From bench to bedside. World Journal of Clinical Cases 2:787-814. DOI: 10.12998/wjcc.v2.i12.787.

Loeschner K, Hadrup N, Qvortrup K, Larsen A, Gao X, Vogel U, Mortensen A, Lam HR, Larsen EH. 2011. Distribution of silver in rats following 28 days of repeated oral exposure to silver nanoparticles or silver acetate. Particle and Fibre Toxicology 8:1-14. DOI: 10.1186/1743-

Peer] reviewing PDF | (2020:11:55546:1:1:NEW 1 Mar 2021) 
489

490

491

492

493

494

495

496

497

498

499

500

501

502

503

504

505

506

507

508

509

510

511

512

513

514

515

516

517

518

519

520

521

522

523

524

525

526

527

528

529

530

531

532

533

534

8977-8-18.

Longo F, Vuotto C, Donelli G. 2014. Biofilm formation in Acinetobacter baumannii. The new microbiologica 37:119-27.

Maguire R, Duggan O, Kavanagh K. 2016. Evaluation of Galleria mellonella larvae as an in vivo model for assessing the relative toxicity of food preservative agents. Cell Biology and Toxicology 32:209-216. DOI: 10.1007/s10565-016-9329-x.

Marx DE, Barillo DJ. 2014. Silver in medicine: The basic science. Burns 40:S9-S18. DOI: 10.1016/j.burns.2014.09.010.

McQueary CN, Actis LA. 2011. Acinetobacter baumannii biofilms: Variations among strains and correlations with other cell properties. Journal of Microbiology 49:243-250. DOI: 10.1007/s12275-011-0343-7.

Morones-Ramirez JR, Winkler JA, Spina CS, Collins JJ. 2013. Silver Enhances Antibiotic Activity Against Gram-negative Bacteria. Science translational medicine 5:1-21. DOI: 10.1126/scitranslmed.3006276.

Muller M. 2018. Bacterial Silver Resistance Gained by Cooperative Interspecies Redox Behavior. Antimicrobial agents and chemotherapy 62:1-10.

National Institute for Health and Care Excellence. 2018. Urinary tract infection (lower): antimicrobial prescribing.

National Institute for Helth and Care Excellence. 2020.Silver dressings. Available at https://bnf.nice.org.uk/wound-management/silver-dressings.html

Oates A, Lindsay S, Mistry H, Ortega F, McBain AJ. 2018. Modelling antisepsis using defined populations of facultative and anaerobic wound pathogens grown in a basally perfused biofilm model. Biofouling 34:507-518. DOI: 10.1080/08927014.2018.1466115.

Pal S, Tak YK, Song JM. 2007. Does the antibacterial activity of silver nanoparticles depend on the shape of the nanoparticle? A study of the gram-negative bacterium Escherichia coli. Applied and Environmental Microbiology 73:1712-1720. DOI: 10.1128/AEM.02218-06.

Peetsch A, Greulich C, Braun D, Stroetges C, Rehage H, Siebers B, Köller M, Epple M. 2013. Silver-doped calcium phosphate nanoparticles: Synthesis, characterization, and toxic effects toward mammalian and prokaryotic cells. Colloids and Surfaces B: Biointerfaces 102:724729. DOI: 10.1016/j.colsurfb.2012.09.040.

Pereira TC, Barros PP de, de Oliveira Fugisaki LR, Rossoni RD, Ribeiro F de C, Menezes RT de, Junqueira JC, Scorzoni L. 2018. Recent advances in the use of Galleria mellonella model to study immune responses against human pathogens. Journal of Fungi 4. DOI: 10.3390/jof4040128.

Politano AD, Campbell KT, Rosenberger LH, Sawyer RG. 2013. Use of silver in the prevention and treatment of infections: Silver review. Surgical Infections 14:8-20. DOI: 10.1089/sur.2011.097.

Raad II, Mohamed JA, Reitzel RA, Jiang Y, Dvorak TL, Ghannoum MA, Hachem RY, Chaftari AM. 2011. The prevention of biofilm colonization by multidrug-resistant pathogens that cause ventilator-associated pneumonia with antimicrobial-coated endotracheal tubes. Biomaterials 32:2689-2694. DOI: 10.1016/j.biomaterials.2010.12.015.

Russell AD, Hugo WB. 1994. Antimicrobial Activity and Action of Silver. Progress in Medicinal Chemistry 31:351-370. DOI: 10.1016/S0079-6468(08)70024-9.

Shah KN, Shah PN, Mullen AR, Chen Q, Southerland MR, Chirra B, DeBerardinis RJ, Cannon CL. 2020. N-Acetyl cysteine abrogates silver-induced reactive oxygen species in human cells without altering silver-based antimicrobial activity. Toxicology Letters 332:118-129.

Peer) reviewing PDF | (2020:11:55546:1:1:NEW 1 Mar 2021) 
535

536

537

538

539

540

541

542

543

544

545

546

547

548

549

550

551

552

553

554

555

556

557

558

559

560

561

562

563

564

565

566

567

568

569

570

571

572

573

574

575

576

DOI: $10.1016 /$ j.toxlet.2020.07.014.

Tacconelli E, Magrini N. 2017. Global priority list of antibiotic-resistant bacteria to guide research, discovery, and development of new antibiotics.

Thallinger B, Argirova M, Lesseva M, Ludwig R, Sygmund C, Schlick A, Nyanhongo GS, Guebitz GM. 2014. Preventing microbial colonisation of catheters: Antimicrobial and antibiofilm activities of cellobiose dehydrogenase. International Journal of Antimicrobial Agents 44:402-408. DOI: 10.1016/j.ijantimicag.2014.06.016.

The European Committee on Antimicrobial Susceptibility Testing. 2019.Breakpoint tables for interpretation of MICs and zone diameters, version 9.0. Available at http://www.eucast.org/clinical_breakpoints/

Tsai CJ-Y, Loh JMS, Proft T. 2016. Galleria mellonella infection models for the study of bacterial diseases and for antimicrobial drug testing. Virulence 7:214-229. DOI: 10.1080/21505594.2015.1135289.

Vaidya MY, McBain AJ, Butler JA, Banks CE, Whitehead KA. 2017. Antimicrobial Efficacy and Synergy of Metal Ions against Enterococcus faecium, Klebsiella pneumoniae and Acinetobacter baumannii in Planktonic and Biofilm Phenotypes. Scientific Reports 7:1-9. DOI: $10.1038 / \mathrm{s} 41598-017-05976-9$.

Vazquez-Muñoz R, Meza-Villezcas A, Fournier PGJ, Soria-Castro E, Juarez-Moreno K, Gallego-Hernández AL, Bogdanchikova N, Vazquez-Duhalt R, Huerta-Saquero A. 2019. Enhancement of antibiotics antimicrobial activity due to the silver nanoparticles impact on the cell membrane. PLOS ONE 14:1-18. DOI: 10.1371/journal.pone.0224904.

Wan G, Ruan L, Yin Y, Yang T, Ge M, Cheng X. 2016. Effects of silver nanoparticles in combination with antibiotics on the resistant bacteria Acinetobacter baumannii. International Journal of Nanomedicine 11:3789-3800. DOI: 10.2147/IJN.S104166.

Wang XW, Wang NZ, Zhang OZ, Zapata-Sirvent RL, Davies JW. 1985. Tissue deposition of silver following topical use of silver sulphadiazine in extensive burns. Burns, including thermal injury 11:197-201. DOI: 10.1016/0305-4179(85)90070-1.

Witkop B. 1999. Paul Ehrlich and His Magic Bullets, Revisited Published by : American Philosophical Society Paul Ehrlich and His Magic Bullets-Revisited. Proc. Am. Phil. Soc. 143:540-557.

Wojda I. 2017. Immunity of the greater wax moth Galleria mellonella. Insect Science 24:342357. DOI: $10.1111 / 1744-7917.12325$.

World Health organisation. 2015. Global Action Plan on Antimicrobial Resistance. WHO Press. DOI: $10.1128 /$ microbe.10.354.1.

Xu FF, Imlay JA. 2012. Silver(I), mercury(II), cadmium(II), and zinc(II) target exposed enzymic iron-sulfur clusters when they toxify Escherichia coli. Applied and Environmental Microbiology 78:3614-3621. DOI: 10.1128/AEM.07368-11.

Zhang F, Smolen JA, Zhang S, Li R, Shah PN, Cho S, Wang H, Raymond JE, Cannon CL, Wooley KL. 2015. Degradable polyphosphoester-based silver-loaded nanoparticles as therapeutics for bacterial lung infections. Nanoscale 7:2265-2270. DOI: 10.1039/c4nr07103d. 


\section{Figure 1}

The growth inhibition of Acinetobacter baumannii exposed to silver acetate is concentration dependent.

Silver acetate was added to exponentially growing cultures at final concentrations of (A) 0.98, (B) 1.95 , (C) 3.91 , (D) 7.81 and (E) $15.60 \mathrm{mg} \mathrm{L}^{-1}$. Cultures were incubated at $37^{\circ} \mathrm{C}$ with shaking and growth monitored via absorbance $\left(\mathrm{OD}_{600}\right)$ every $20 \mathrm{~min}$ for $24 \mathrm{~h}$. (F) Panel shows growth in the presence of all concentrations of silver acetate for comparison. $\mathrm{N}=3$, error bars are omitted for clarity, but standard deviations were all within the range 0.0006 0.1664 . 

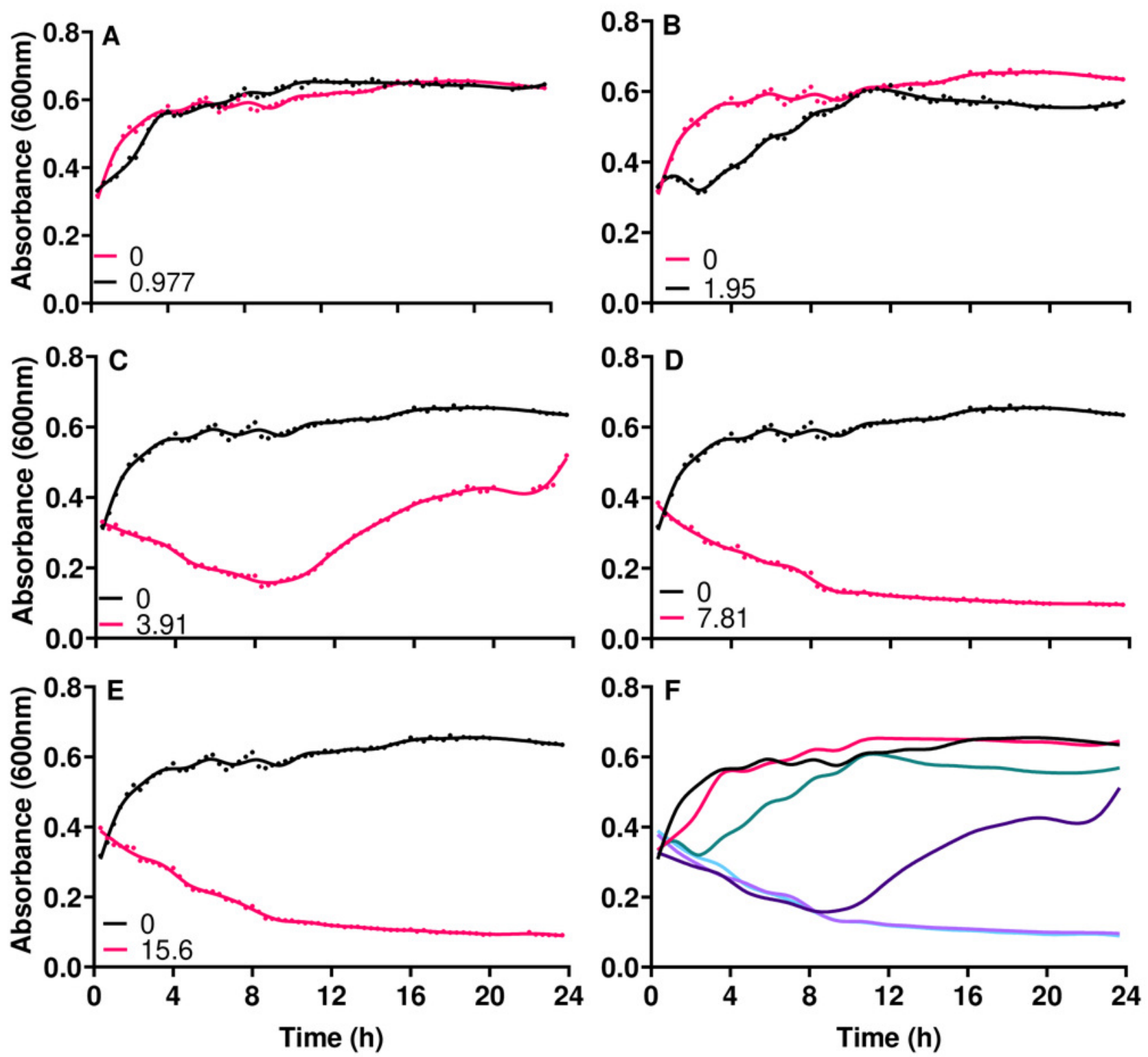


\section{Figure 2}

The bactericidal activity of silver acetate against exponentially growing Acinetobacter baumannii is concentration and time dependent.

Batch cultures of $A$. baumannii were grown at $37^{\circ} \mathrm{C}$ with shaking to early exponential phase when silver acetate was added at final concentrations of $0,0.98,1.95,3.91,7.81$ or 15.60 $\mathrm{mg} \mathrm{L}^{-1}(\mathrm{t}=0 \mathrm{~h})$. Cultures were incubated for a further $24 \mathrm{~h}$ with viability determined at twohour intervals to eight hours post-exposure $(t=2-8 \mathrm{~h})$ and at $24 \mathrm{~h} . \mathrm{N}=3 \pm$ SEM.

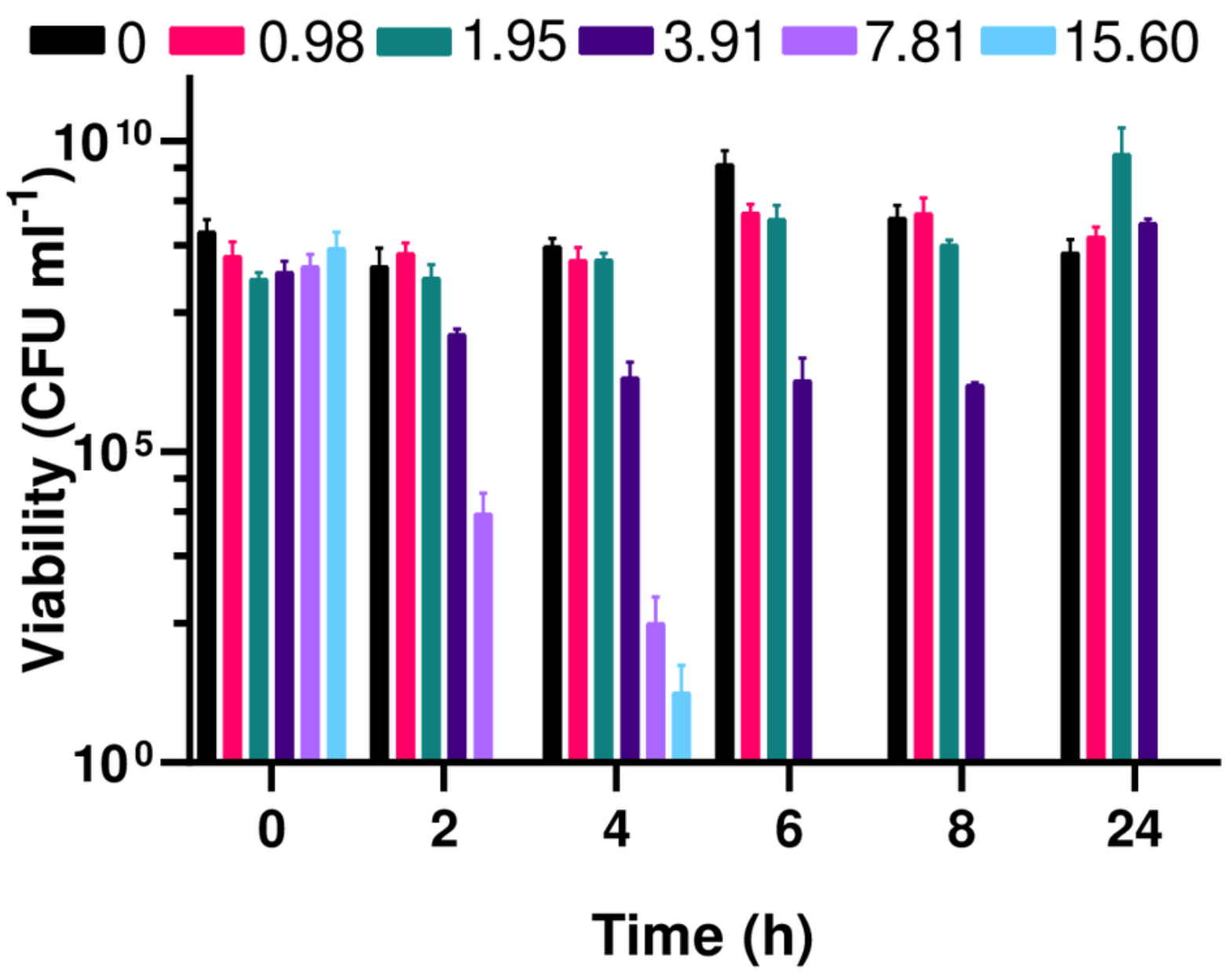




\section{Figure 3}

Biofilm production is significantly reduced in the presence of silver acetate.

A. baumannii cultures were incubated statically in Mueller-Hinton broth at $37^{\circ} \mathrm{C}$ in 24 -well plates in the presence of varying concentrations of silver acetate $\left(0-7.8 \mathrm{mg} \mathrm{L}^{-1}\right)$. (A) After incubation the wells were washed and stained with crystal violet to determine the amount of biofilm formed $\left(\mathrm{OD}_{540}\right)$. Differences in biofilm formed between the lower $\left(0-1.95 \mathrm{mg} \mathrm{L}^{-1}\right)$ and higher (3.9 - 7.8 $\mathrm{mg} \mathrm{L}^{-1}$ ) concentrations of silver acetate were highly significant (ANOVA and Tukeys multiple comparison test, $* * * * P<0.0001$ ). (B) After incubation, biofilms were disaggregated and bacterial viability was determined. Significant differences in biofilm formation were observed between the lowest $\left(0-0.49 \mathrm{mg} \mathrm{L}^{-1}\right)$ and highest concentrations of silver acetate (3.9 - 7.8 $\mathrm{mg} \mathrm{L}^{-1}$, ANOVA and Tukey's multiple comparison, $* * \mathrm{P}=0.0005$ 0.003) $\mathrm{N}=3 \pm$ SEM. 


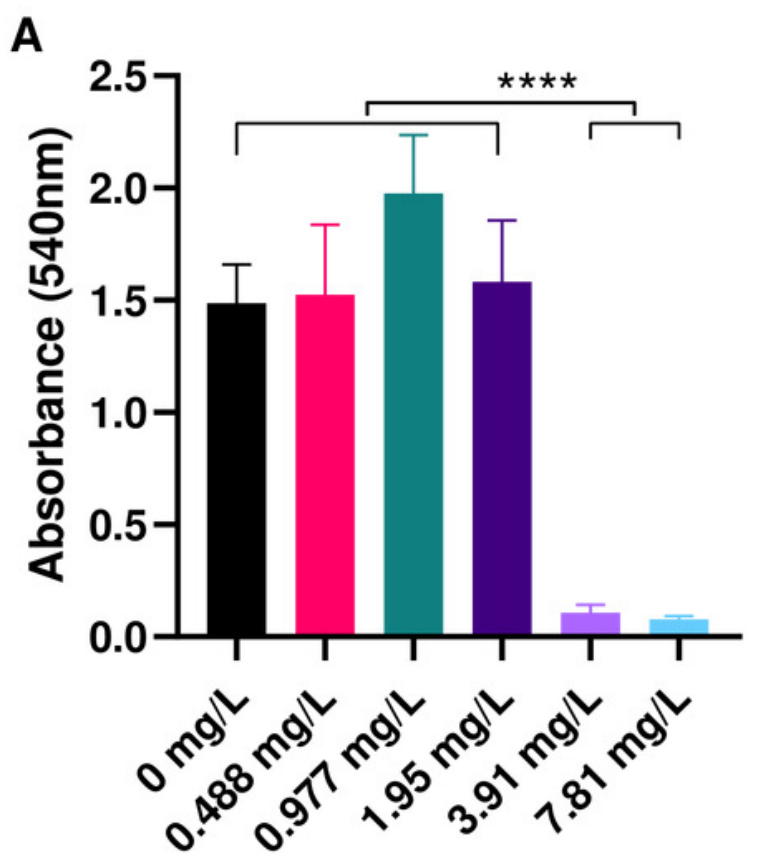

Silver acetate concentration $\left(\mathrm{mg} \mathrm{L}^{-1}\right)$

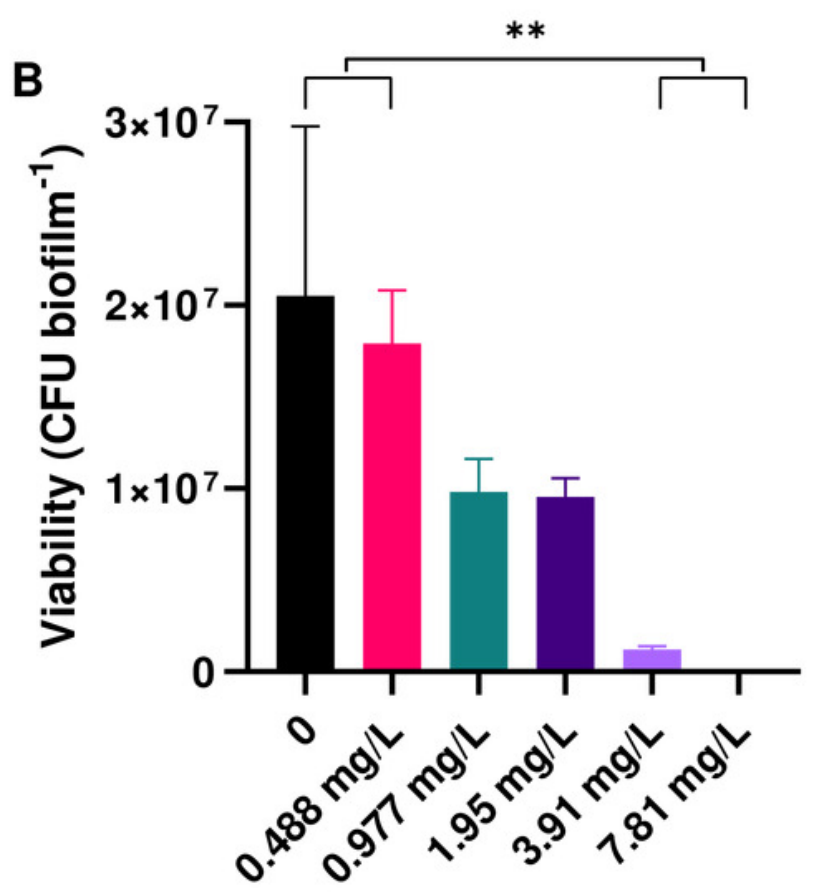

Silver acetate concentration $\left(\mathrm{mg} \mathrm{L}^{-1}\right)$ 


\section{Figure 4}

Infection of Galleria mellonella larvae with varying concentrations of Acinetobacter baumannii causes changes in health and lethality.

Groups of $G$. mellonella larvae were injected with $10 \mu$ of $A$. baumannii containing between

$1.7 \times 10^{2}$ to $1.7 \times 10^{7}$ cells per larvae, control groups were injected with PBS or were not injected. (A) Larval survival was monitored every $24 \mathrm{~h}$ for $96 \mathrm{~h}$ post-injection. The dotted line corresponds to $80 \%$ larval death (**** $\mathrm{P}<0.0001, \mathrm{~N}=30$ larvae per condition) (B) Melanisation was recorded for all larvae every $24 \mathrm{~h}$ for $96 \mathrm{~h}$ post-injection a standard melanisation score $\left(* \mathrm{P}=0.0423,{ }^{*} \mathrm{P}=0.001-0.0063,{ }^{*} * * \mathrm{P}=0.0006,{ }^{*} * * * \mathrm{P}<0.0001, \mathrm{~N}=30\right.$ larvae per concentration, \pm SEM). (C+D) Standard melanisation scoring.
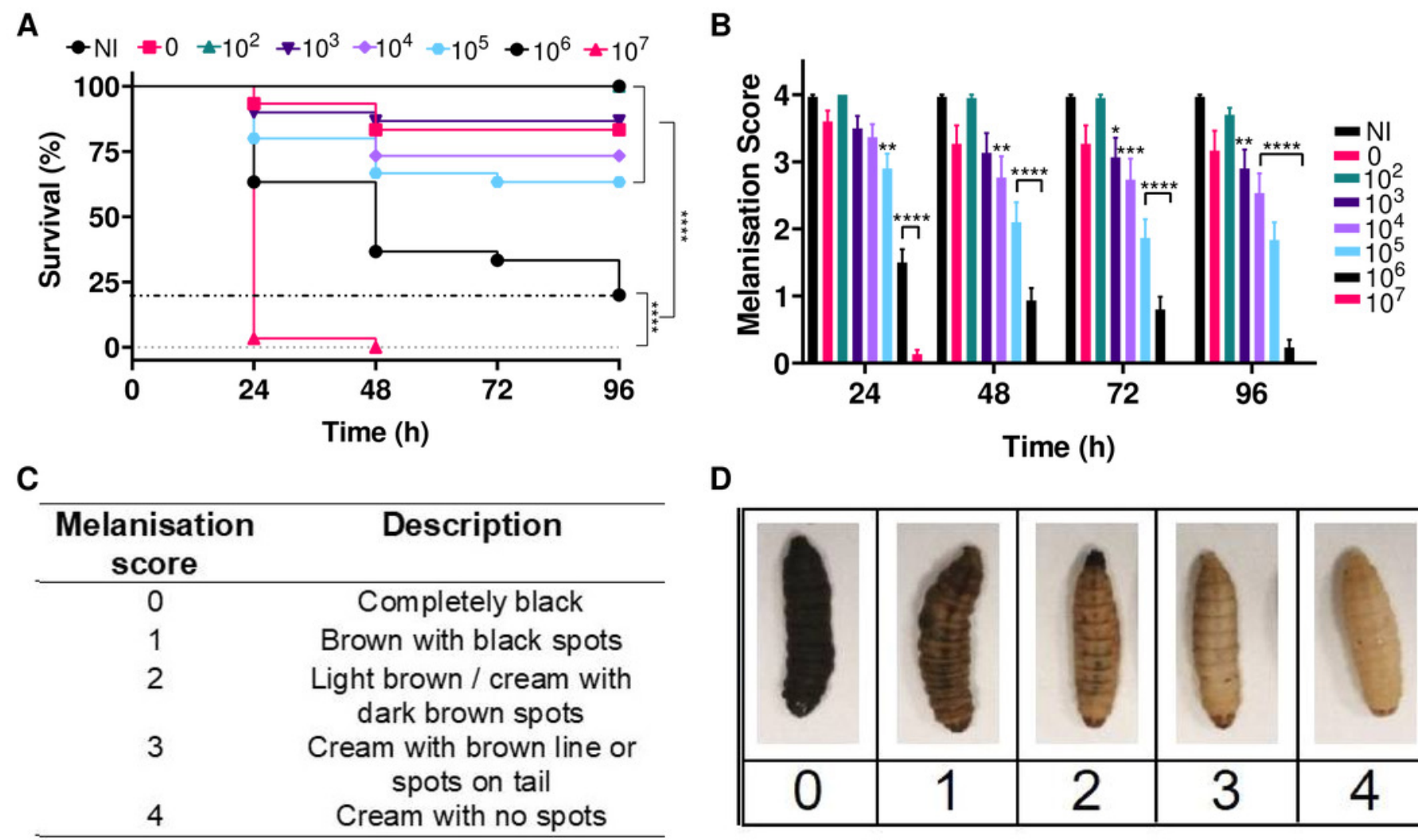

D

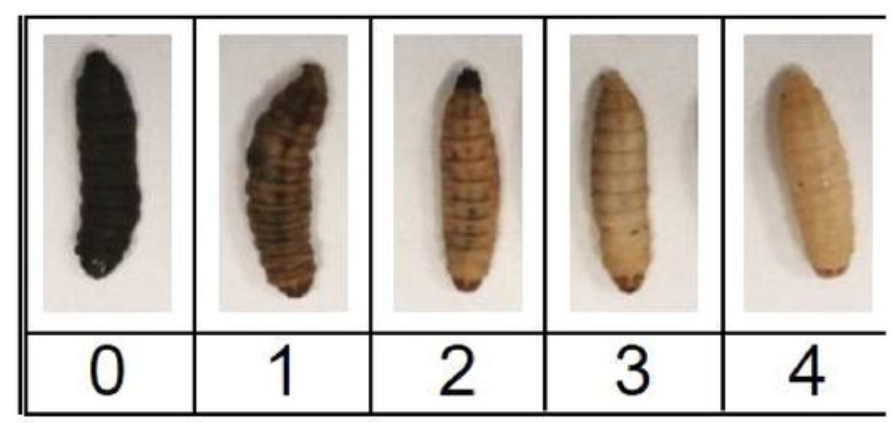


Figure 5

A range of medically relevant silver acetate concentrations shows minimal toxicity to Galleria mellonella.

Groups of Galleria mellonella larvae were injected with $10 \mu \mathrm{l}$ of silver acetate between 0 - 80 $\mathrm{mg} \mathrm{kg}^{-1}$ animal weight. (A) Larval survival was monitored every $24 \mathrm{~h}$ for $96 \mathrm{~h}$ post-injection ( $\mathrm{N}$ $=30$ larvae per condition). (B) Melanisation was recorded for all larvae every $24 \mathrm{~h}$ for $96 \mathrm{~h}$ post-injection and assigned a standard melanisation score $(* * * \mathrm{P}=0.0006, \mathrm{~N}=30$ larvae per condition, \pm SEM).
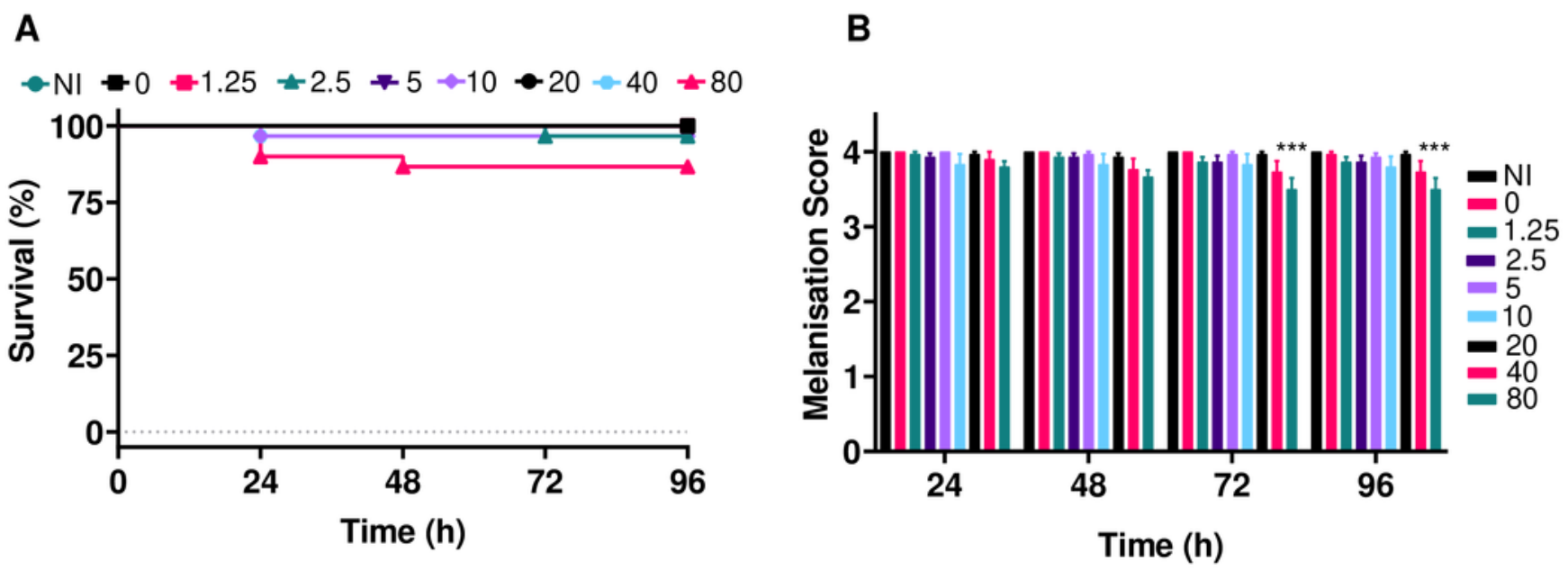
Figure 6

Silver acetate treatment of Galleria mellonella larvae infected with Acinetobacter baumannii reduced lethality and improved overall health of the larvae.

Groups of Galleria mellonella larvae were injected with $10 \mu$ of $A$. baumannii containing either $1.7 \times 10^{5}$ or $1.7 \times 10^{6}$ cells per larvae, 30 min post-infection groups of larvae were administered either 10 or $20 \mathrm{mg} \mathrm{kg}^{-1}$ silver acetate as treatment. $\mathrm{N}=70$ larvae per condition. $(A+B)$ Survival and $(C+D)$ melanisation were recorded every $24 \mathrm{~h}$ for $96 \mathrm{~h}$ post-injection. $(A+B) * P<0.05$. $(C+D)$ Error bars show SEM, $* P=0.0168-0.0235, * * P=0.0015-0.0089$.

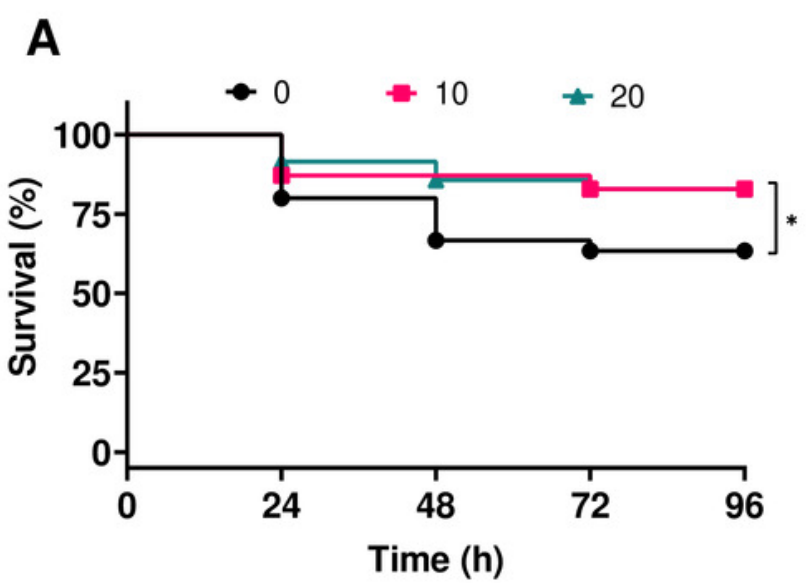

$1.7 \times 10^{5} \mathrm{CFU} /$ larvae

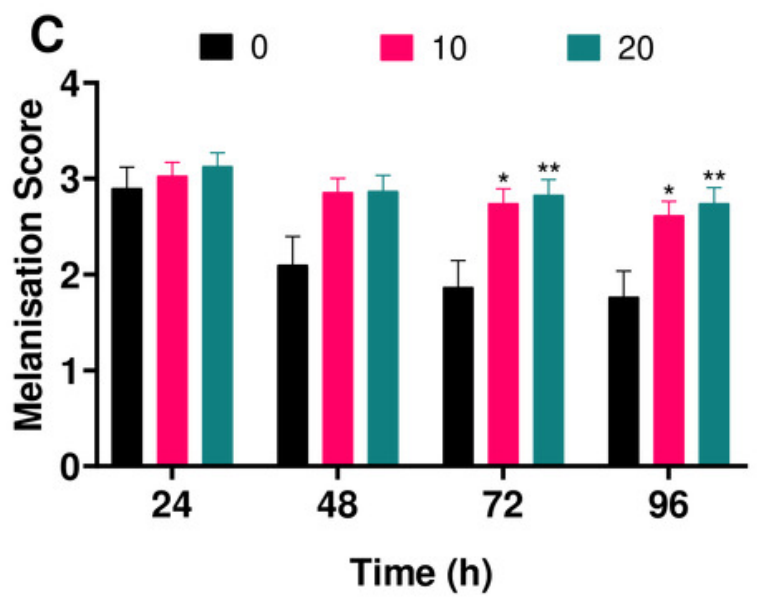

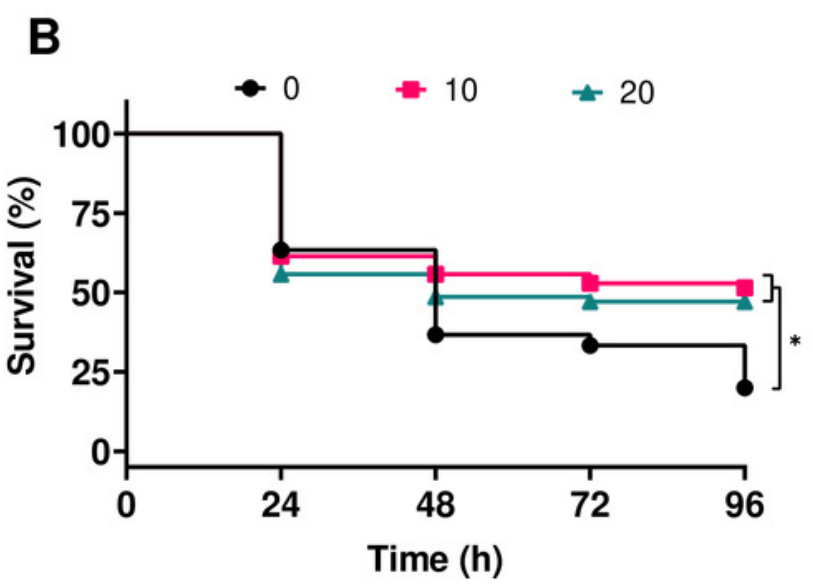

$1.7 \times 10^{6} \mathrm{CFU} /$ larvae

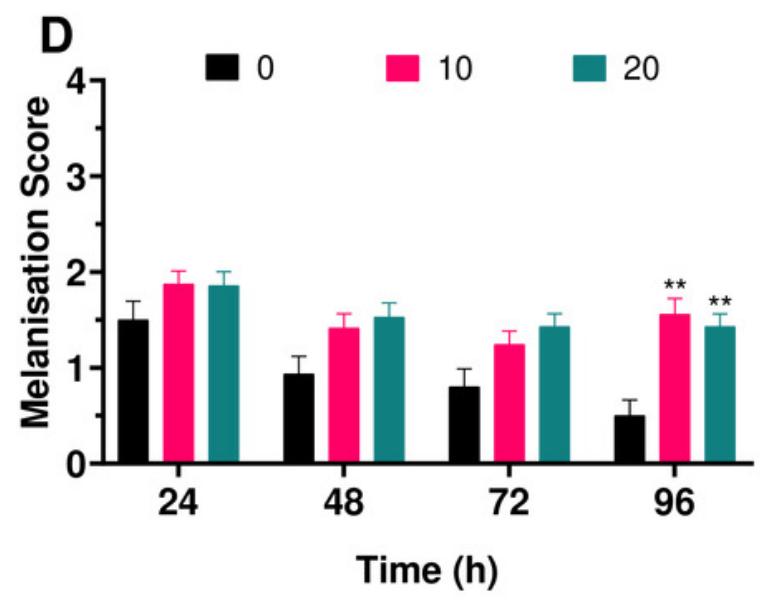




\section{Table $\mathbf{1}$ (on next page)}

Minimum inhibitory and bactericidal concentrations for silver acetate against a range of A. baumannii strains demonstrates significant antimicrobial activity.

Standard MIC and MBC assays were performed against a range of $A$. baumannii strains grown in Mueller-Hinton Broth in a 96-well plate. Where the MBC appears to be higher than the MIC statistical analysis showed no significant difference (paired T-test $P=0.2839, N=3 \pm S D$ ). Meropenem MIC's determined for comparison to silver activity. 


\begin{tabular}{llccc}
\hline \multirow{2}{*}{$\begin{array}{l}\text { Bacterial } \\
\text { Strain }\end{array}$} & Type / origin & \multicolumn{2}{c}{ Silver acetate } & Meropenem \\
\cline { 2 - 4 } & & $\begin{array}{c}\text { MIC } \text { gg L }^{-1} \\
\text { (SD) }\end{array}$ & $\begin{array}{c}\text { MBC } \text { mg L L }^{-1} \\
\text { (SD) }\end{array}$ & $\begin{array}{c}\text { MIC } \text { mg L L }^{-1} \\
\text { (SD) }\end{array}$ \\
\hline ATCC 17978 & Clinical isolate & $4.56(1.59)$ & $9.11(3.19)$ & $0.194(0.0659)$ \\
NCTC 12156 & Type strain & $3.91(0)$ & $7.81(0)$ & $0.556(0.110)$ \\
NCTC 13301 & $\begin{array}{l}\text { Type D carbapenemase } \\
\text { reference strain OXA-23 }\end{array}$ & $3.91(0)$ & $6.64(2.62)$ & $>10(0)$ \\
NCTC 13302 & $\begin{array}{l}\text { Type D carbapenemase } \\
\text { reference strain OXA-25 } \\
\text { NCTC 13305 }\end{array}$ & $3.91(0)$ & $7.81(0)$ & $>10(0)$ \\
& $\begin{array}{l}\text { Type D carbapenemase } \\
\text { reference strain OXA-58 }\end{array}$ & $4.56(1.59)$ & $13.03(9.49)$ & $5.47(1.64))$ \\
\hline
\end{tabular}

1 